\title{
Viscoelastic Properties of Polypropylene Reinforced with Mica in $T_{\alpha}$ and $T_{\alpha c}$ Transition Zones
}

\author{
S. Farzaneh and A. Tcharkhtchi \\ PIMM, CNRS UMR 8006, Arts et Métiers ParisTech, 151 boulevard de l'Hôpital, 75013 Paris, France
}

Correspondence should be addressed to S. Farzaneh, sedigheh.farzaneh@ensam.eu

Received 15 March 2011; Accepted 9 May 2011

Academic Editor: Harald W. Ade

Copyright () 2011 S. Farzaneh and A. Tcharkhtchi. This is an open access article distributed under the Creative Commons Attribution License, which permits unrestricted use, distribution, and reproduction in any medium, provided the original work is properly cited.

\begin{abstract}
The viscoelastic properties of mica-reinforced polypropylene (PP) was studied in temperature range between $-30^{\circ} \mathrm{C}$ and $120^{\circ} \mathrm{C}$. WLF equation permits determining the free volume fraction in $\alpha$ and $\alpha c$ transitions regions. It was shown that the value of this parameter is lower for $\alpha c$ transition, indicating that the free volume and thermal expansion of $\alpha$ region is more than that of $\alpha c$ region. At a $40 \%$ loading level, it was shown that the storage and loss modulus of mica-filled PP increases dramatically (in comparison with the pure polypropylene). The relative modulus does not change significantly at glassy state but it increases for the temperature higher than $T_{g}$. It was also shown that mica does not affect the glass transition temperature but results in an increase in $\alpha c$ transition.
\end{abstract}

\section{Introduction}

There are several advantages with polypropylene reinforced with mica. This composite has relatively high stiffness, highdimensional stability, low thermal conductivity, low cost, and so forth The effect of mica on properties of polypropylene especially the mechanical properties was the subject of several studies.

In a general way, the mechanical properties of a filled polymer depend on several parameters, the size, aspect ratio, and geometry of the filler, its weight percent, the dispersion of the particles in the matrix, the adhesion between matrix and filler, and so forth.

Several authors have studied the effect of rigid fillers like mica on mechanical and dynamic mechanical properties of polypropylene [1-5]. They have shown the filler effect on the properties of this polymer in glassy and rubbery states and more particularly on glass transition temperature $[6,7]$. It has been also demonstrated that the effect of fillers on viscoelastic properties of polymers in glassy state and rubbery state is not the same. The mineral fillers do not shift the glass transition temperature of the polymer but this transition zone will be broadened because of the filler particles. It was shown that the mechanism of damping of filled polymers depends on particle-particle friction, particle-polymer friction, and change of polymer properties by adsorption onto filler particles [8].

In the case of semicrystalline polymers, it is well known that beside $\alpha$ transition there is another transition called $\alpha c$ transition $\left(T_{\alpha c}\right)$ for the temperatures higher than $T_{g}$ in rubbery state [9]. This transition is mainly related to the crystalline phase. In this case, it is interesting to study the effect of filler on this transition. Unfortunately there is not a significant research work to show this effect on $\alpha c$ transition of semicrystalline polymers.

In this study, we have tried to show the effect of mica on the properties, especially thermomechanical properties, of polypropylene in the zone of $\alpha$ and $\alpha c$ transition. WLF equation has been used to determine the free volume fraction of amorphous phase in these two regions.

\section{Materials}

The polypropylene used in this work was supplied by Borealis, under the trade name BE 182B, and mica (with $3.5 \mu \mathrm{m}$ as diameter and a form factor of 60 ) was supplied by CMMP Company. 


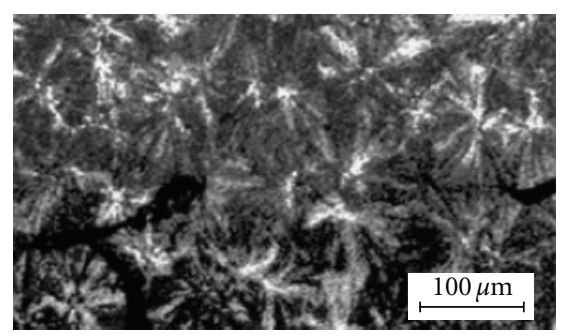

(a)

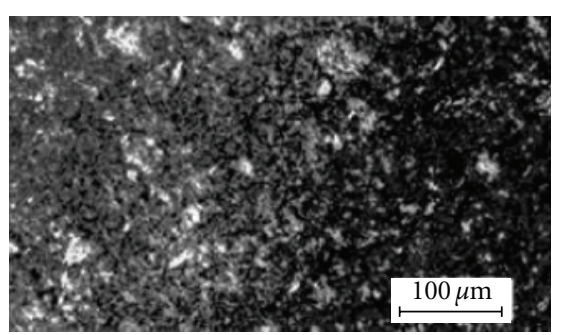

(b)

FIgURE 1: Structure of unfilled PP (a) and filled PP with 40\% of MICA-SOFT (b) under optical microscope.

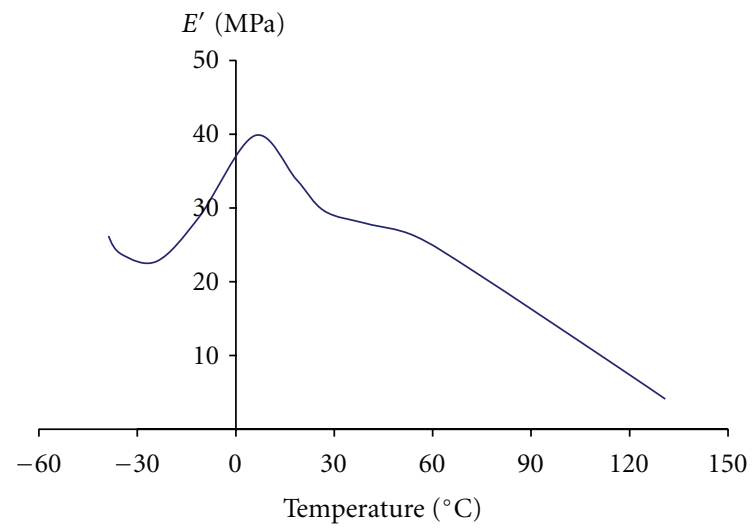

FIGURE 2: Loss modulus variation with temperature during DMTA experiment on unfilled PP.

The compounding was carried out in single screw extruder (SAMAFOR BG 45) with a screw rate of $40 \mathrm{rpm}$. The temperature range of extrusion was set between $165^{\circ} \mathrm{C}$ and $210^{\circ} \mathrm{C}$. The filled polypropylene has been prepared by $40 \%$ of weight of mica. After extrusion, the granules were dried for a period of $4 \mathrm{~h}$ at $90^{\circ} \mathrm{C}$ in a pulsed oven, before being injected in a DK CODIM $175-400$ press at $160-210^{\circ} \mathrm{C}$ temperature range. Samples were kept over 10 days at $23^{\circ} \mathrm{C}$ and $50 \% \mathrm{RH}$ to allow stabilisation and relaxation.

\section{Dynamic Mechanical Thermal Analysis}

Dynamic mechanical testing has long been employed in the study of the viscoelastic response of polymers. The DMTA equipment (from TA Company) was calibrated before the tests. The viscoelastic spectra, $E^{\prime}$ (storage modulus), $E^{\prime \prime}$ (loss modulus), and $\tan \delta$ (loss factor) were recorded in dual cantilever bending measurement system with an amplitude of $50 \mu \mathrm{m}$. The multifrequency (from $0.1 \mathrm{~Hz}$ to $100 \mathrm{~Hz}$, heating rate of $0.5^{\circ} \mathrm{C} / \mathrm{min}$ ) and single frequency (at $1 \mathrm{~Hz}$, heating rate of $2^{\circ} \mathrm{C} / \mathrm{min}$ ) tests were recorded between -40 and $120^{\circ} \mathrm{C}$.

The test specimens with the geometry of $38 \mathrm{~mm} \times 10 \mathrm{~mm}$ $\times 4 \mathrm{~mm}$ were obtained from injection-moulded plates. $T_{g}$ was taken as the temperature corresponding to the maximal loss modulus.

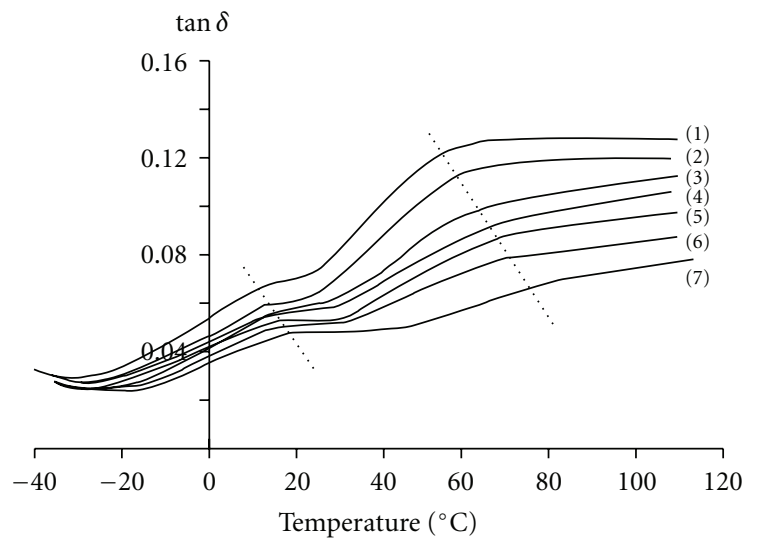

FIGURE 3: Effect of frequency on DMTA spectrum $(\tan \delta)$ of pure PP: (1) $0.1 \mathrm{~Hz}$, (2) $0.3 \mathrm{~Hz}$, (3) $1 \mathrm{~Hz}$, (4) $5 \mathrm{~Hz}$, (5) $10 \mathrm{~Hz}$, (6) $50 \mathrm{~Hz}$, and (7) $100 \mathrm{~Hz}$.

\section{Results and Discussion}

Figure 1 shows the crystalline texture of unfilled and filled polypropylene. It is clearly shown that the presence of mica particles has modified the morphology of crystalline phase. In pure PP the spherulites (of about $100 \mu \mathrm{m}$ diameter) are relatively regular. They have the form of polygons, the result of interdiffusion of sperolites (Figure 1(a)).

In filled PP the formation of crystalline phase during crystallization has been affected by the mica particles (Figure 1(b)). In this case, it is practically impossible to observe the spherulites in the core. It is not also possible to observe the mica particles in the matrix.

It seems that the mica particles play the role of nucleating agent during crystallization. So the result is the formation of small spherulites. Having the role of nucleating agent, the particles of mica will remain in centre of spherulites.

\section{Thermomechanical Analysis}

The viscoelastic spectrum $\left(E^{\prime \prime}\right)$ in temperature range between $-30^{\circ} \mathrm{C}$ and $150^{\circ} \mathrm{C}$ is shown in Figure 2. This curve reveals the presence of the two following transitions:

(i) the peak at about $10^{\circ} \mathrm{C}$ corresponding to the glass transition temperature of polypropylene, 


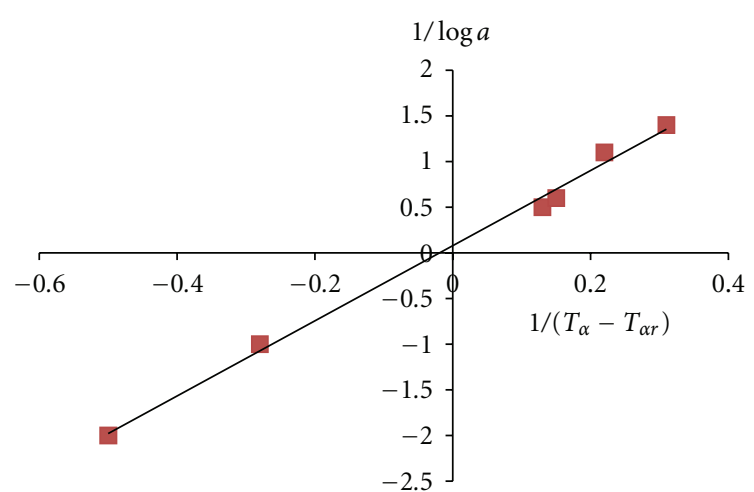

FIGURE 4: Linear regression of WLF equation in the region of $\alpha$ transition.

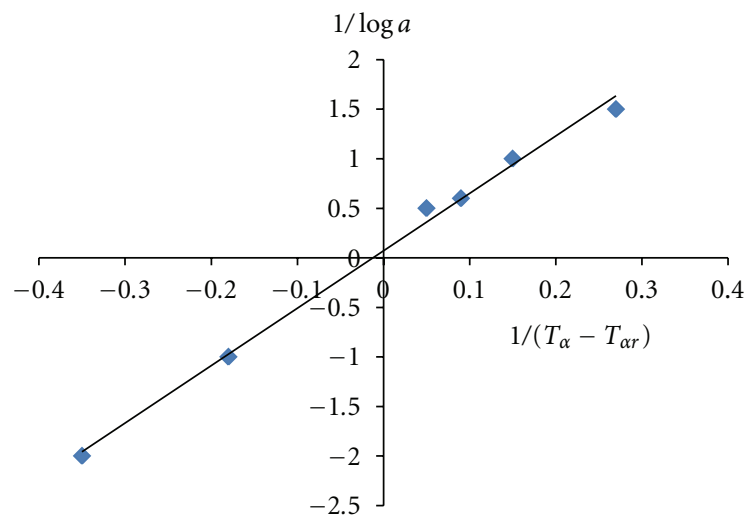

FIGURE 5: Linear regression of WLF equation in the region of $\alpha c$ transition.

(ii) the shoulder on the curve at about $50^{\circ} \mathrm{C}$, after the glass transition temperature. This shoulder is indeed related to $\alpha c$ transition.

\section{Influence of Frequency on $\alpha$ and $\alpha c$ Transitions}

Different studies have been performed to identify the nature of $\alpha c$ transition [9].

Figure 3 shows the results of thermomechanical tests at different frequencies from 0.1 to $100 \mathrm{~Hz}$. One can clearly distinguish the presence of two transition zones on all of the curves.

In order to study the effect of frequency on $\alpha$ and $\alpha c$ transitions, WLF equation is used to follow the relationship between the frequency and temperature. Shift factors $a_{T}$ were determined from the classical master curve method.

WLF equationis

$$
\log a_{T}=\frac{C_{1}\left(T_{\alpha}-T_{\alpha r}\right)}{C_{2}+\left(T_{\alpha}-T_{\alpha r}\right)} .
$$

$T_{\alpha r}(1 \mathrm{~Hz})$ was arbitrarily taken as reference temperature. By linear regression method, WLF equation has been

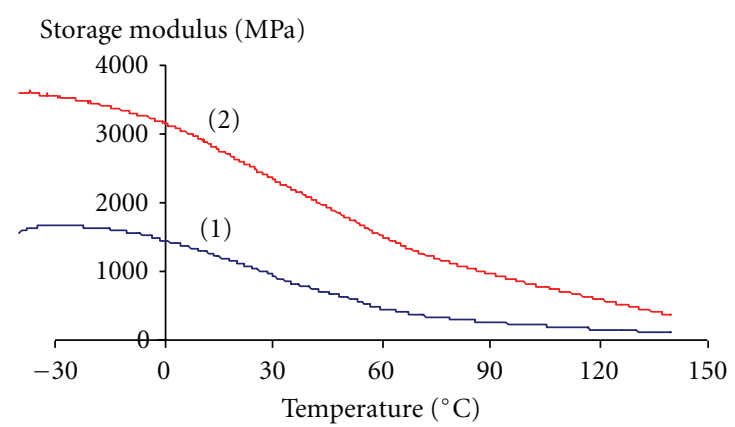

Figure 6: Storage modulus variation of unfilled (1) and mica-filled (2) polypropylene.

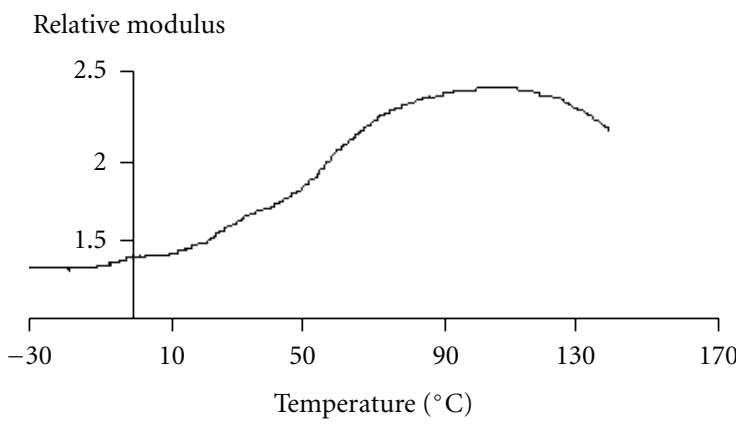

FIGURE 7: Relative storage modulus variation.

transformed to the following linear equation: $1 / \log a_{T}=$ $\left(C_{2} / C_{1}\right) 1 /\left(T_{\alpha}-T_{\alpha r}\right)+1 / C_{1}$. Then $1 / \log a_{T}$ was plotted against $1 /\left(T_{\alpha}-T_{\alpha r}\right)$. Straight lines with a correlation coefficient near to one were obtained in two regions, $\alpha$ and $\alpha c$ transition regions (Figures 4 and 5), showing that the materials under study obey the WLF time-temperature equivalence principle.

The WLF constants $C_{1}=B / 2.303 f_{g}$ and $C_{2}=f_{g} / \Delta \alpha$ are related to two important physical properties of this polymer, free volume fraction, $f_{g}$, and thermal expansion coefficient, $\Delta \alpha$.

$\Delta \alpha$ has been determined by dilatometric method. $f_{g}$ can be determined by the following equation: $f_{g}=$ $\sqrt{(B \cdot \Delta \alpha / 2.303) \cdot\left(C_{2} / C_{1}\right)}$, where $B \approx 1$ and $C_{2} / C_{1}$ is the slope of above straight line.

All of these values are listed in Table 1.

This modelling lets us to determine the value of free volume fraction, $f_{g}$, and thermal expansion coefficient, $\Delta \alpha$, in two cases. The results are shown in Table 1 .

These results call for the following comments.

(1) The free volume fraction in $\alpha c$ transition region is less than that of $\alpha$ transition region. This is true because the molecular chains are more compact in the region of $\alpha c$ transition near the crystalline phase.

(2) The same is for thermal expansion coefficient. It seems that thermal dimensional stability of polymer in the region of $\alpha c$ is more in respect to the $\alpha$ transition region. This is also related the fact that the chain molecular mobility of amorphous phase near to the crystalline zone is lower than other parts of this phase. 


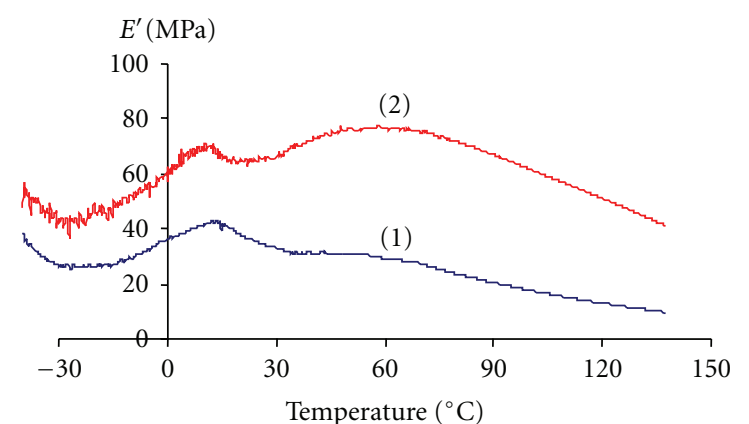

FIGURE 8: Loss modulus variation of unfilled (1) and mica-filled (2) polypropylene.

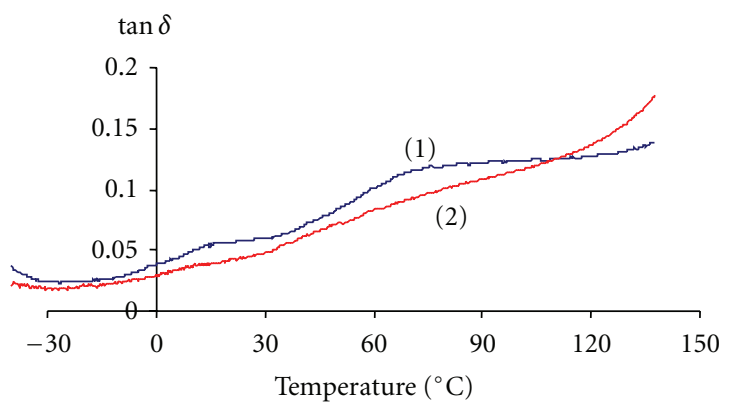

Figure 9: Damping variation of unfilled (1) and mica-filled (2) polypropylene.

TABLE 1: $\Delta \alpha$ and $f_{g}$ for transition $\alpha$ and transition $\alpha c$ zones.

\begin{tabular}{lccc}
\hline Transitions & $C 2 / C 1$ & $f_{g}$ & $\Delta \alpha\left(K^{-1}\right)$ \\
\hline$\alpha$ & 4.03 & 0.0277 & $4.410^{-4}$ \\
$\alpha c$ & 5.94 & 0.0233 & $2.110^{-4}$ \\
\hline
\end{tabular}

\section{Effect of Mica on Storage Modulus}

The storage modulus, $E^{\prime}$, of polypropylene increases significantly by addition of mica (Figure 6). In the first regard, it seems that the effect of mica is more important in glassy state than that in rubbery state, but this is not accurate when we follow the variation of relative storage modulus $\left(E_{\text {mica filled } \mathrm{PP}}^{\prime} / E_{\text {unfilled PP }}^{\prime}\right)$ versus temperature (Figure 7$)$. At temperatures lower than $T_{g}$, the relative modulus remains constant. It increases to reach a maximum value at $105^{\circ} \mathrm{C}$ and then decreases. The increase of relative modulus $\left(T>T_{g}\right)$ has been related to the fact that the filler agglomerates can be broken more easily in glassy state and are more rigid in rubbery state [4]. It seems generally that the rubbery state is widening with filler addition. We can also note that it is difficult to appreciate the effect of mica on the position of $T_{g}$ and $T_{\alpha c}$ with the storage modulus variation curve.

\section{Effect of Mica on Loss Modulus}

The loss modulus, $E^{\prime \prime}$, generally increases with mica addition (Figure 8). There are two peaks corresponding to the two reported transitions $T_{\alpha}$ and $T_{\alpha c}$ [9]. $T_{\alpha}$, which is generally

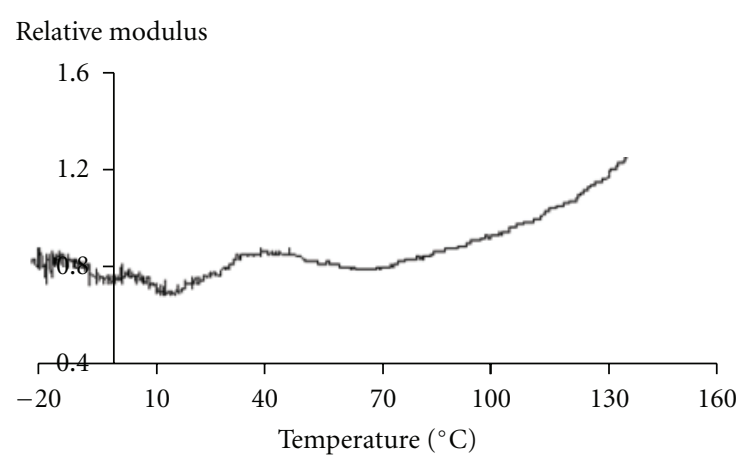

FIGURE 10: Relative damping variation.

related to the glass transition temperature, is not affected by mica addition. It is about $15^{\circ} \mathrm{C}$ for both samples. $T_{\alpha c}$, which corresponds to chains mobility near the crystallite surface [9], increases from $45^{\circ} \mathrm{C}$ (for unfilled PP) to almost $60^{\circ} \mathrm{C}$ (for mica-filled PP). This behaviour is probably due to the high concentration of mica particles in the boundary region between the amorphous and crystalline phases. In fact during crystallisation, the small mica particles will be essentially pushed out of the crystalline phase. The high concentration of mica in the boundary region makes the chain mobility difficult. So it is necessary to supply more energy. $T_{\alpha c}$, which is characteristic of this region, will be then affected. In the amorphous phase (far from boundary region) the mica concentration is not so high, and then its effect on the position of $T_{\alpha}$ (which is related to glass transition temperature) is not very significant. Moreover, it seems that the filler is the cause of the broadening of the second transition region.

\section{Effect of Mica on Damping}

Damping increases with temperature. The $\tan \delta$ curve of the unfilled PP (Figure 9) presents two small peaks (shoulders) corresponding to $T_{\alpha}$ and $T_{\alpha c}$. For the PP filled with mica, it is difficult to distinguish these transitions. Damping decreases a little with the addition of mica. However, for temperatures higher than $110^{\circ} \mathrm{C}$, the damping of PP filled with mica becomes higher than the unfilled one. The damping phenomenon of filled polymers is very complex. It is related to filler-filler friction, filler-polymer friction, and the conformational and morphological change of the polymer in contact with the filler. The relative damping curve (Figure 10) decreases in glass transition and $\alpha$ transition regions. This behaviour can be shown by two minimums on this curve.

\section{Conclusions}

During this study, we have shown that mica particles modify the morphology of polymer.

The thermomechanical properties are also modified by the presence of mica particles. The storage modulus increases significantly because of the influence of $40 \%$ of Mica. Relative 
storage modulus shows that this effect is more important in rubbery state than that in glassy state. The effect in $\alpha c$ region is the maximum. The study on loss modulus and damping spectra shows that mica particles do not have any significant effect on $\alpha$ transition temperature, but the influence on $\alpha c$ transition region is important. Relating to the pure PP, the filled polymer loses more energy in the region of $\alpha c$ transition.

Finally, it was shown that WLF equation explains well the behaviour of polymer in both regions, $\alpha$ and $\alpha c$ transitions. The values of $f_{g}$ and $\Delta \alpha$ obtained by this method confirm that there is less free volume in amorphous phase near the crystalline phase than the other parts of this phase and thermal dimensional stability of $\alpha c$ transition region more than $\alpha$ transition region.

\section{References}

[1] M. F. Omar, H. M. Akil, and Z. A. Ahmad, "Static and dynamic compressive properties of mica/polypropylene composites," Materials Science and Engineering: A, vol. 528, no. 3, pp. 15671576, 2011.

[2] L. E. Nielsen, "Dynamic mehcanical properties of filled polymers," Applied Polymer Symposia, no. 12, pp. 249-265, 1969.

[3] A. Agbossou, A. Bergeret, K. Benzarti, and N. Alberola, "Modelling of the viscoelastic behaviour of amorphous thermoplastic/glass beads composites based on the evaluation of the complex Poisson's ratio of the polymer matrix," Journal of Materials Science, vol. 28, no. 7, pp. 1963-1972, 1993.

[4] J. P. Trotignon and A. Tcharkhtchi, "Fatigue behaviour of filled polymers," Macromolecular Symposia, no. 108, pp. 231-245, 1996.

[5] J. P. Trotignon, B. Sanschagrin, M. Piperaud, and J. Verdu, "Mechanical properties of mica-reinforced polypropylene composites," Polymer Composites, vol. 3, no. 4, pp. 230-238, 1982.

[6] M. A. López-Manchado and M. Arroyo, "Thermal and dynamic mechanical properties of polypropylene and short organic fiber composites," Polymer, vol. 41, no. 21, pp. 7761-7767, 2000.

[7] J. L. Acosta, A. Linares, and M. C. Ojeda, "Influence de la structure interfaciale sur les propriétés thermiques et dynamiques de composites de polypropylène á base de sépiolites superficiellement acetalées," European Polymer Journal, vol. 21, no. 9, pp. 821-824, 1985.

[8] L. E. Nielsen and R. F. Landel, Particle-Filled Polymers, Mechanical Properties of Polymers and Composites, Marcel Dekker, New York, NY, USA, 2nd edition, 1994.

[9] M. Botev, Ph.D. thesis, Orsay University, 1999. 

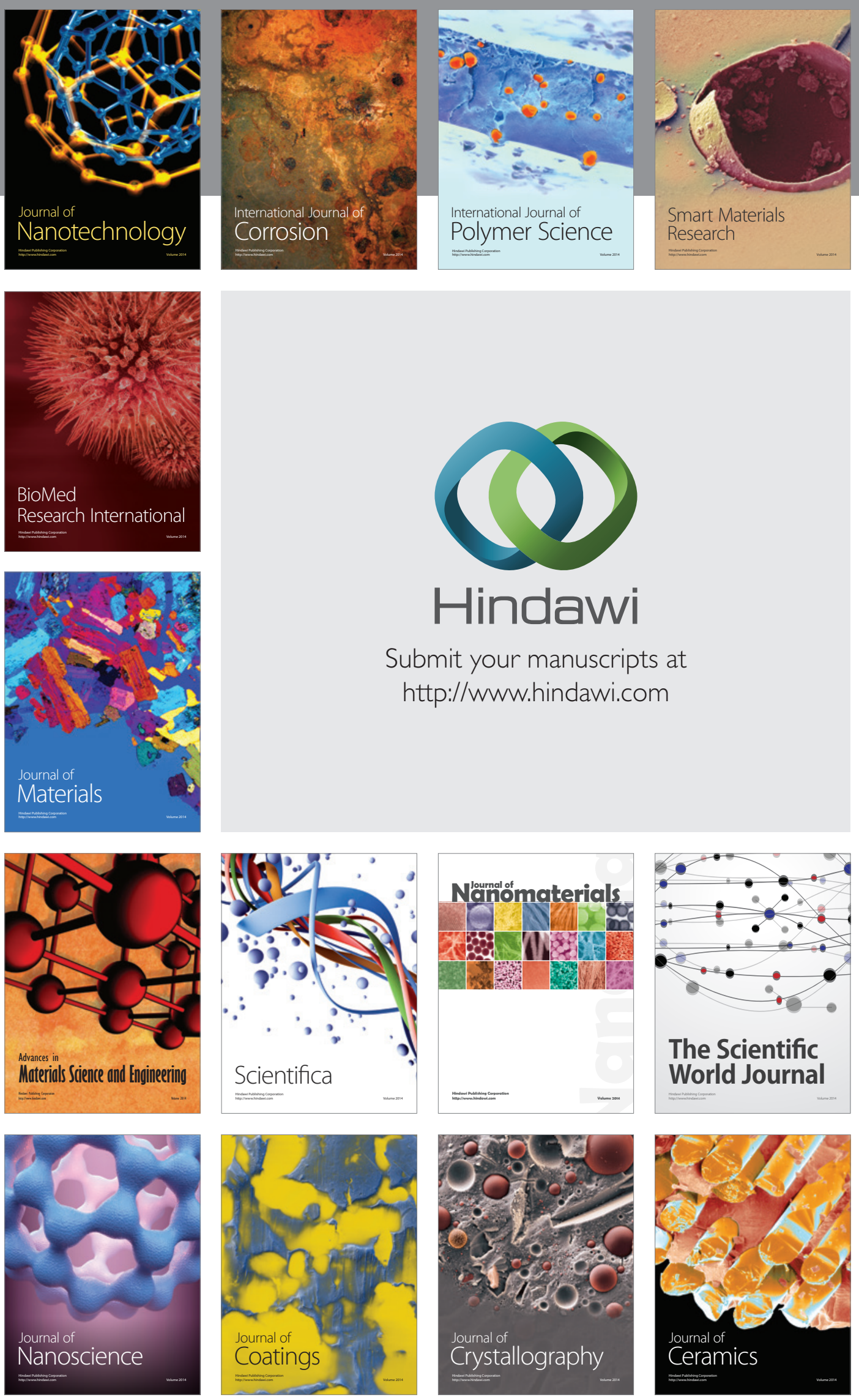

The Scientific World Journal

Submit your manuscripts at

http://www.hindawi.com

\section{World Journal}

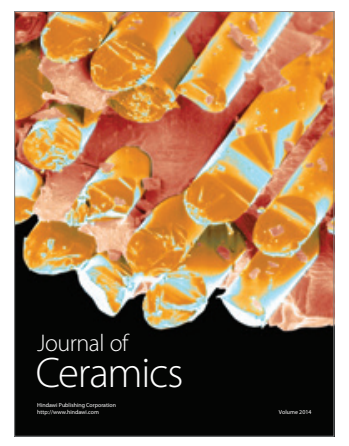

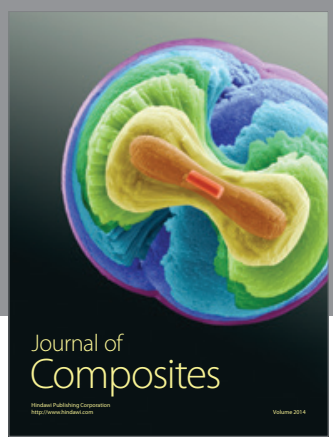
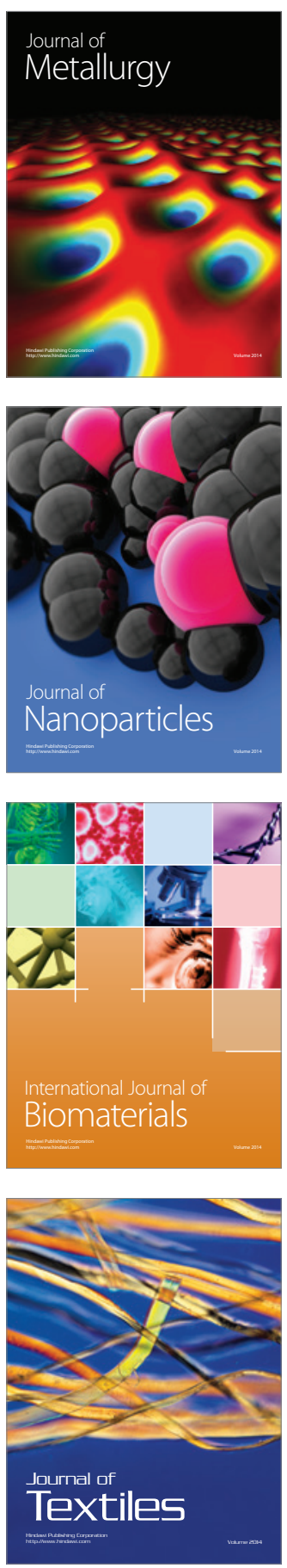